Alex Sinclair $\mathrm{PhD}$
Jos Van Bergen
Health and Welfare Canada

REFERENCE

1 Medical Devices Alert No. 101. Leakage and breakage of anaesthetic bottles of forane and possible damage to metal filling adaptors. Health Protection Branch, Ottawa, January $24,1992$.

\section{Anaesthetists and the right to die}

To the Editor:

With its recent judgement in the case of Nancy B., the judiciary system in Quebec has upheld the right of the mentally competent patient to request cessation of life support treatment.' This judgement reflects the ethical position to which a majority of physicians and society in general have evolved.

To every right corresponds a duty. If, after mental competence has been demonstrated and all other options considered at length, a patient decides to exercise his/her right to request cessation of life support treatment, then it becomes the duty of the patient's physician to assist the patient in withdrawing technological support while ensuring that the patient does not suffer.

For the ventilator-dependent patient, such as Nancy B., terminating treatment humanely necessitates the administration of doses of sedative drugs which by themselves might cause death even in a normal individual. As the fine line between preventing suffering and actively terminating life becomes inevitably obscured, physicians become uncomfortable with carrying out this duty. Because of this and because of their fear of not giving enough, physicians may be tempted to request the services of anaesthetists to assist them in carrying out their duty. In the case of Nancy B., an anaesthetist was present at her bedside along with her doctor when sedation was administered and the ventilation disconnected. ${ }^{2}$

As society in general, and the medical community in particular, is likely to evolve gradually toward the recognition of an increasing number of indications for "humane" cessation of treatment (i.e., cessation of treatment with sedation) and as the boundary between cessation of treatment with sedation and active euthanasia becomes more obscured, anaesthetists may be increasingly requested to render such services. A recent article in the
New England Journal of Medicine ${ }^{3}$ went as far as suggesting that anaesthetists are ideally suited to perform active euthanasia and should probably be the only physicians licensed to do so, if and when this practice becomes acceptable.

As anaesthetists, we should reflect on the implications of this situation for our specialty. Do we want our role to evolve according to these demands that are likely to be addressed to us?

We believe that such acts as administering heavy sedation for withdrawal of life support treatment are the duty of the attending physician, as he or she is primarily responsible for the outcome of the ethical decision process. To invite an anaesthetist to attend or to actually administer the medication is not only unnecessary, it is also undesirable. It is unnecessary because the administration of generous doses of long-lasting sedative drugs, ideally suited for this situation, is in the realm of competence of many, if not all, physicians. It is undesirable because it will encourage the formation of a group of physicians who may become desensitized to such interventions while allowing those who are involved in the ethical decision process to distance themselves from the consequences of their decision. This may eventually allow for laxity in the ethical decision process.

We fear the personal cost to anaesthetists of helping to carry out decisions in which they are not, and should not, in most circumstances, be involved. Furthermore, we do not want to become associated in the minds of our patients with the act of terminating life, as this might well interfere with their ability to trust that we will do our utmost to support their own life.

Giséle Hemmings MD

Fred C. Salevsky MD

Paul A. Sloan MD

Mark Angle MD

Fiona E. Ralley MD

Daniel Chartrand MD

Sally Weeks MD

Anne Moore MD

Marlene Gauthier MD

Richard Catchlove MD

Raymond Hasel MD

Jean-François Courval MD

Department of Anaesthesia

Royal Victoria Hospital

Montreal, Quebec

\section{REFERENCES}

1 Cour Supérieure, Province de Québec, District de Québec. Nancy B. demanderesse vs Hôtel Dieu de Québec, défende- 
resse et Docteur Daniele Marceau et le procureur général de Québec, mis en cause.

2 Came B. The Last Goodbye. Nancy B. exercises her right to die. MacLean's February 24, 1992. p 50.

3 Benrubi GI. Euthanasia - The need for procedural safeguards. N Engl J Med 1992; 326: 197-9.

\section{Four-centre study of anaesthetic outcomes}

\section{To the Editor:}

We would like to comment on the very interesting and topical series of papers written by $\mathrm{M}$. Cohen et al. ${ }^{1-3}$ They are to be congratulated for the incredible amount of time and effort which they have expended in collecting and analyzing data on 37,665 anaesthetics. However, we do have some concerns regarding certain aspects of the data collection and interpretation.

Data were gathered using a combination of chart review and patient interview. The authors carefully note at least 15 factors which may effect the validity of the data collected by these techniques. Of importance, many of these elements differed among the various institutions studied. Other potential problems with the data collection involve the process of performing patient interviews. As all practising clinicians are aware, patients are often unreliable historians, especially for comfort-related problems. Indeed, the actual act of asking whether a patient has a specific symptom may itself increase the incidence of findings, due to auto-suggestion. Patients may also be influenced by external factors such as suggestions by surgical or nursing staff (which may be institutionspecific) and preconceived notions of "usual anaesthetic complications" (particularly sore throat and nausea/vomiting). Furthermore, some patients will clearly have preexisting dementia or psychological unreliability and, as such, must be excluded from this type of data collection. Since the patient interviews were an integral part of the process assessing the frequency of postoperative complications, the "disturbing" incidence of sore throat, nausea, headache and backache in outpatients alluded to in the third study ${ }^{3}$ may be at least partly attributed to the above factors. It would be interesting to know the frequency of these complications which were graded as severe, since considering just the severe symptoms may diminish the effect of some of the preceding potential sources of bias.

Although it is difficult to know the exact impact of the plethora of factors which may bias the data collected in these studies, it is very likely that, at least in combination, they could effect the reliability and validity of that data. Since the conclusions of any study are limited by the quality of the initial data, it is probably inappropriate to derive anything more than very preliminary conclusions from the data of the current studies.

To help assess the validity of the methods used in these studies, the investigators quantified the reliability of two specific data collection techniques: the postoperative patient interview questionnaire, and the panel assessment of causation of ten hypothetical cases. Although the former method appeared to be reliable, with interrater agreement of $>95 \%$, the latter technique exhibited poor interrater agreement, with a kappa value of only 0.38 . Despite this latter observation, the authors conclude that "the ratings of actual cases could be reliably carried out by the audit committees at each hospital." This conclusion, is not justified since the investigators did not quantitate the reliability of the causation assessment for real cases and there is no reason to anticipate that the assessment of real cases would be more reliable than that of the hypothetical cases. To justify the above conclusion, the authors refer to the higher degrees of reliability obtained using similar types of assessments reported in previous studies. We fail to understand the validity of this line of reasoning. Indeed, it would be interesting to discover why the interrater agreement of the current study differed from that previously reported.

The conclusions of any study ultimately depend upon the statistical validity. As the number of comparisons performed on the same body of data increases, the likelihood of any comparison becoming significant due to chance alone also increases. Accordingly, as more and more subsets of data are analyzed the acceptable $P$ value for a 1:20 chance of alpha error decreases, in a manner analagous to the Bonferroni correction for multiple $t$ tests. ${ }^{4}$ In the second and third papers, several large tables are shown representing comparisons of many different variables. Statistical significance was set at $P \leq 0.05$ in the second study and the "more conservative value of $P \leq$ $0.01^{\text {" }}$ in the third. Probably even lower $P$ values of $<0.001$ or less would have been more appropriate for most of these tables, based on the Bonferroni correction of $P=0.05 / n$ ( $n=$ number of comparisons). The investigators' choice of $P$ value may have contributed to the occurrence of some unexpected correlations, such as the association between preoperative hypertension and difficult intubation. Such a relationship has no apparent biological plausibility and, as such, may represent an artifact of the statistical analysis.

Finally, occurrence screening studies of this sort are generally not considered an end in themselves but are useful in planning future prospective, randomized clinical 